\title{
MUNDIALIZAÇÃO DA EDUCAÇÃO E RESPONSABILIDADE SOCIAL
}

\author{
Camila Azevedo Souza ${ }^{1}$ \\ camilaazevedosouza@yahoo.com.br
}

\section{Resumo:}

Esse trabalho analisa a influência das formulações dos organismos internacionais nas políticas educacionais e suas relações com a atuação empresarial no meio educacional, evidenciando a responsabilidade social como um movimento organizado mundialmente. A perspectiva epistemológica é o materialismo histórico e o referencial teórico-metodológico é baseado nas formulações de Antonio Gramsci, que contribuem na análise de como os organismos internacionais atuam nas relações de hegemonia construindo uma nova sociabilidade capaz de manter a coesão social. As análises confirmam que os organismos internacionais atuam enquanto verdadeiros aparelhos privados de hegemonia da burguesia mundial capazes de induzir políticas públicas fundamentadas na teoria do capital humano e na ideologia da sociedade do conhecimento, concebendo o investimento em educação como incremento para a competitividade global. Ou seja, consolidam uma (con)formação voltada para o capital que reafirma os princípios da responsabilidade social e legitima a mundialização da educação nos moldes de um capitalismo de face humanizada.

Palavras-chave: educação; organismos internacionais; responsabilidade social.

\footnotetext{
${ }^{1}$ Formada em Pedagogia pela Universidade Federal de Juiz de Fora e Mestranda do Programa de Pós-Graduação em Educação da Universidade Federal Fluminense, no qual está vinculada ao NEDDATE - Núcleo de Estudos, Documentação e Dados sobre Trabalho e Educação.
}

TrabalhoNecessário - www.uff.br/trabalhonecessario; Ano 11, № 17/2013. 


\section{Trabalhonecessário}

Issn: 1808 - 799X

ano 11, no $17-2013$

\section{Abstract:}

This study analyzes the formulations from the international organizations, their influence over education policies and the relations with the business activities on the education context in order to highlight the impact of social responsibility as an organized worldwide movement. The epistemological approach is the Historical Materialism and the theoretical and methodological framework is based on the formulations of Antonio Gramsci, used to understand how these organisms are linked to the hegemonic relations which reaffirm the social responsibility by building a new sociability to maintain the social cohesion. The results confirm that the international organizations are powerful hegemonic private apparatus of the bourgeois world capable of inducing public policies based on the human capital theory and on the ideology of the knowledge society, by considering the investment on education as an increment for the global competitiveness. These organizations maintain the (con)formation toward the capital which reaffirms the principles of social responsibility and the globalization of education through an humanized face of capitalism.

Keywords: education; international organizations; social responsibility. 


\section{Trabalhonecessário}

Issn: 1808 - 799X

ano 11, no $17-2013$

\section{INTRODUÇÃO:}

Uma vez que formar o homem-coletivo para o trabalho/vida sob a concepção burguesa de mundo se constitui em referência geral do projeto educacional hegemônico, o presente artigo analisa a difusão dos princípios da responsabilidade social pelos organismos internacionais, tendo em vista as implicações para o fenômeno da mundialização da educação e as repercussões para política educacional e formação humana.

Alicerçado no materialismo histórico como perspectiva epistemológica e nas contribuições do pensador marxista Antonio Gramsci enquanto referencial teórico-metodológico, o trabalho apresenta parte dos resultados encontrados em "Organismos Internacionais e Responsabilidade Social na Educação: uma (con)formação voltada para o capital”2 (SOUZA, 2013), uma pesquisa qualitativa com base em fontes documentais de quatro organismos internacionais ${ }^{3}$.

A partir do referencial gramsciano, buscou-se verificar em que medida os organismos internacionais atuam na sociedade civil enquanto representantes dos interesses burgueses, exercendo o papel de aparelhos privados de hegemonia capazes de dar direção a propostas pedagógicas legitimadoras da hegemonia dominante através de um complexo processo educativo que procura subordinar moral e intelectualmente toda a sociedade (GRAMSCI, 2000).

Além das formulações gramscianas, o trabalho também está fundamentado em contribuições de outros autores marxistas.

Considerando que as reformas educacionais implementadas nos países dependentes, em que pesem as especificidades locais, seguiram as mesmas orientações traçadas pelos organismos internacionais, Melo (2003) elabora o

\footnotetext{
${ }^{2}$ Monografia desenvolvida sob orientação do Prof. Dr. André Silva Martins e apresentada junto ao Curso de Pedagogia da Universidade Federal de Juiz de Fora, como requisito parcial à obtenção do título de Bacharel em Educação.

${ }^{3}$ Organização das Nações Unidas para a Educação, a Ciência e a Cultura (Unesco), Organização para a Cooperação e Desenvolvimento Econômico (OCDE), Banco Mundial e Programa de Promoção da Reforma Educativa na América Latina (PREAL).
}

TrabalhoNecessário - www.uff.br/trabalhonecessario; Ano 11, № 17/2013. 


\section{Trabalhonecessário}

Issn: 1808 - 799X

ano 11, no $17-2013$

conceito de mundialização da educação, um fenômeno contextualizado na dinâmica de internacionalização do capital e que faz parte do projeto neoliberal com a intenção de uniformizar a "integração global" e de instituir novas condicionalidades para empréstimos e doações para o setor educacional, o que repercute na construção da sociabilidade capitalista (MELO, 2003).

Atualizando as formulações gramscianas na sociedade brasileira, Neves (2005) analisa o neoliberalismo da Terceira Via como a fase contemporânea do capitalismo, a partir dos anos 1990, e explicita os desdobramentos da mundialização da educação no Brasil em um movimento mais amplo denominado de a nova pedagogia da hegemonia, que envolve um conjunto de estratégias de repolitização da política ${ }^{4}$ para educar o consenso no mundo contemporâneo de maneira a reafirmar os interesses neoliberais de transferir responsabilidades para a sociedade civil através do estímulo à assistência social e à responsabilidade social (NEVES, 2005).

Em Martins (2009a), apropriamo-nos da responsabilidade social como a nova ideologia da classe empresarial no Brasil e no mundo. Segundo o autor, essa ideologia vem configurando politicamente o empresariado na direita para 0 social, uma força social de novo tipo que defende a possibilidade de conciliar os fundamentos de uma economia de mercado com justiça social na perspectiva de consolidação de um capitalismo de face humanizada.

Esse movimento também contribui na consolidação do programa neoliberal da Terceira Via através de seus princípios norteadores: a "sociedade civil ativa" reafirma uma sociedade sem antagonismos através das noções de colaboracionismo, responsabilidade social e liberdade de escolhas individuais; o "novo Estado democrático" procura promover uma reforma da aparelhagem estatal através da transferência de suas responsabilidades para a sociedade civil sugerindo um "Estado necessário" ou "gerencial"; enfim, o "individualismo como

\footnotetext{
${ }^{4}$ Segundo Neves (2005), as estratégias da repolitização da política estão fundamentadas em soluções individuais, na pequena política e na privatização e fragmentação das políticas sociais.
}

TrabalhoNecessário - www.uff.br/trabalhonecessario; Ano 11, № 17/2013. 


\section{Trabalhonecessário}

Issn: 1808 - 799X

ano $11, \mathrm{n}=17-2013$

valor moral radical" difunde a atuação de um cidadão reflexivo com espírito empreendedor, iniciativa individual, senso de responsabilidade social e capacidade de se mobilizar no espaço comunitário (MARTINS, 2009a).

A cultura de avaliação na escola em conjunto com a política de responsabilização de professores e instituições escolares (accountability), assim como as diversas parcerias entre escolas públicas e organizações empresariais, são expressões significativas da legitimação da hegemonia empresarial e da disseminação dos princípios da Terceira Via em projetos educativos.

Essa influência da cultura burguesa nos planos, diretrizes e estratégias educacionais vem se configurando em uma regressão da educação escolar de direito social a um serviço mercantil, impulsionando a consolidação de políticas educacionais baseadas na teoria do capital humano e sua renovação, da qual emergem as noções de sociedade do conhecimento, qualidade total, pedagogia das competências, empregabilidade e empreendedorismo (FRIGOTTO, 2011).

Com o objetivo de analisar essas contradições na definição de uma agenda global para a educação, o presente artigo está organizado em três momentos, além dessa Introdução e das Considerações finais, tendo em vista: (1) as diretrizes educacionais dos organismos internacionais no movimento histórico; (2) a articulação dessas diretrizes com os princípios da responsabilidade social; e (3) o conteúdo das formulações sobre educação no início do século XXI através de dados empíricos de dois organismos internacionais.

\section{CONTEXTUALIZAÇÃO HISTÓRICA DOS ORGANISMOS INTERNACIONAIS: A PROBLEMÁTICA DA EDUCAÇÃO}

A compreensão das influências dos organismos internacionais no âmbito das políticas públicas educacionais exige uma análise de suas diretrizes políticas no movimento histórico.

TrabalhoNecessário - www.uff.br/trabalhonecessario; Ano 11, № 17/2013. 


\section{Trabalhonecessário}

Issn: 1808 - 799X

ano 11, no $17-2013$

Primeiramente, ressalta-se a tradição do Brasil em recorrer à cooperação internacional no âmbito educacional desde os "Acordos MEC-Usaid" de 1950. A inserção orgânica da United States Agency for International Development (Usaid) no projeto de reforma universitária de 1968 é uma expressão da sua capacidade de influenciar o sistema educacional brasileiro naquela conjuntura (VIEIRA, 2001).

O Banco Mundial foi criado em 1944, conjuntamente com o FMI (Fundo Monetário Internacional), na conferência de Bretton Woods, tendo em vista a reestruturação dos países no pós-guerra. A preocupação específica com a pobreza surgiu a partir de 1968 com a gestão McNamara. Nos anos 1980, marcados pelos programas de ajuste estrutural e pela imposição de condicionalidades para a concessão de empréstimos, abriu-se espaço para a intervenção do organismo no âmbito das políticas públicas e para o estímulo do "Consenso de Washington" como um receituário a ser seguido pelos países em desenvolvimento (SOARES, 1998).

Os critérios para a concessão de créditos significam uma grande influência do Banco Mundial nas agendas educacionais dos países, pois através da visão economicista de bancos internacionais, baseada em noções de critérios gerenciais e de eficiência, busca-se ajustar a educação ao modelo global (FONSECA, 1997).

Segundo Fonseca (1997), a importância do Banco Mundial cresceu nos anos 1990 devido a atuação na organização da Conferência Mundial da Educação para Todos em Jomtien, em $1990^{5}$, e da Conferência de Nova Delhi ${ }^{6}$, em 1993. Essas conferências foram capazes de influenciar diretamente o Plano Decenal de Educação para Todos, elaborado pelo Ministério da Educação e do

\footnotetext{
5 A Conferência Mundial da Educação para Todos foi organizada pelo Banco Mundial conjuntamente com outros organismos internacionais, como PNUD (Programa das Nações Unidas para o Desenvolvimento), UNICEF (Fundo das Nações Unidas para a Infância) e Unesco.

${ }^{6}$ A Conferência de Nova Delhi apresentava como suas diretrizes a ênfase do ensino primário e a importância da escolaridade da mulher tendo em vista sua inserção no mercado de trabalho (FONSECA, 1997).
} 


\section{Trabalhonecessário}

Issn: 1808 - 799X

ano 11, no $17-2013$

Desporto $^{7}$ (FONSECA, 1997), evidenciando convergências no que se refere à concepção de educação como responsabilidade compartilhada por toda a sociedade (VIEIRA, 2001).

Uma vez que o Banco Mundial ${ }^{8}$ se constitui em uma agência de formulação político-econômica com a missão de ordenar o capitalismo nos países periféricos por meio de empréstimos financeiros e assessorias políticas, esse organismo pode ser considerado um intelectual coletivo construtor e legitimador da hegemonia capitalista, sendo que sua dependência ao governo dos Estados Unidos, sua configuração histórica e a postura de suas direções revelam que as bases do projeto hegemônico que orienta suas ações estão alicerçadas na concepção de mundo dominante naquele país (PEREIRA, 2009).

Nessa mesma perspectiva, Neves (2010) evidencia que o Banco Mundial atende aos interesses econômicos norte-americanos e que o acordo de Bretton Woods tem o poder de reafirmar a hegemonia estadunidense e difundir a nova sociabilidade de tipo americana - american way of life.

A Organização das Nações Unidas para a Educação, a Ciência e a Cultura (Unesco) foi criada em 1945, com o objetivo de promover a cooperação internacional entre seus associados nas áreas de educação, ciências, cultura e comunicação, e tem reafirmado os princípios norteadores do neoliberalismo da Terceira Via como maneira de manter a coesão social (NEVES e PRONKO, 2008). Apesar de ter se destacado, durante o século $X X$, pelo papel estratégico em relação à formação para o trabalho, "perde essa prerrogativa depois que os EUA, sua maior fonte de financiamento, dela se retira, em 1984, provocando com

\footnotetext{
7 Para mais informações sobre os acordos do MEC com o Banco Mundial, como o Projeto Edurural entre 1980 e 1987 e o Projeto Nordeste concluído em 1998, ver VIEIRA (2001).

${ }^{8}$ Pereira (2009) evidencia a complexidade institucional do Grupo Banco Mundial através de suas sete organizações: Banco Internacional para a Reconstrução e o Desenvolvimento (BIRD); Associação Internacional de Desenvolvimento (AID); Corporação Financeira Internacional (CFI); Centro Internacional para Conciliação de Divergências em Investimento (CICDI); Agência Multilateral de Garantia de Investimentos (AMGI); Instituto do Banco Mundial (IBM); Painel de Inspeção.
}

TrabalhoNecessário - www.uff.br/trabalhonecessario; Ano 11, № 17/2013. 


\section{Trabalhonecessário}

Issn: 1808 - 799X

ano 11, no $17-2013$

esse afastamento sua associação subalternizada ao Banco Mundial" (NEVES e PRONKO, 2008, p.97).

A publicação em 1996 do Relatório para a UNESCO da Comissão Internacional sobre Educação para o Século XXI, presidida por Jacques Delors, se constitui em um marco importante da atuação desse organismo internacional ${ }^{9}$.

Explicitando um contexto de mundialização do capital $^{10}$, Duarte (2006) analisa o papel da Unesco nesse relatório e revela que os quatro pilares considerados pela Comissão como as bases da educação para o novo século aprender a conhecer, aprender a fazer, aprender a viver juntos e aprender a serse constituem em desdobramentos do lema "aprender a aprender", no qual a concepção de educação como um processo permanente legitima um discurso que "acaba por jogar água no moinho dos esforços internacionais para adequar a educação ao processo de sobrevivência do capitalismo" (DUARTE, 2006, p.54).

Tendo como universo de análise o contexto da América Latina e Caribe, Melo (2003) evidencia que a mundialização hegemônica do capital se constitui em uma nova fase do processo de internacionalização do capital, sendo a mundialização da educação capaz de legitimar um programa hegemônico de homogeneização e redirecionamento de políticas educacionais.

Cabe destacar o protagonismo dos organismos internacionais em consolidar a mundialização da educação, assim como a mudança na trajetória histórica das propostas e ações do FMI, do Banco Mundial e da Unesco, pois se passa de um discurso mais preocupado com o crescimento econômico nos anos 1980 para a defesa de um capitalismo de "face humanizada" nos anos 1990 (MELO, 2003).

\footnotetext{
${ }^{9}$ No Brasil foi publicado em 1998.

${ }^{10}$ Duarte (2006) utiliza a concepção de mundialização do capital de François Chesnais para desconstruir o conceito de globalização, ressaltando um processo de adaptação ao mercado mundial e de desregulamentação do mercado interno. Segundo Chesnais (1996) o termo inglês de "globalização" oculta o papel da mundialização de criar uma rede hierarquizada responsável pela polarização entre os países do oligopólio mundial e os países da periferia, naturalizando a marginalização dos países em desenvolvimento.
}

TrabalhoNecessário - www.uff.br/trabalhonecessario; Ano 11, № 17/2013. 


\section{Trabalhonecessário}

Issn: 1808 - 799X

ano 11, no $17-2013$

No período das reformas educacionais entre os anos 1980 e 1990, como parte das reformas estruturais, os discursos e as atuações do Banco Mundial e do FMI revelam que a educação surge como uma possibilidade de redução da pobreza com base nas noções da teoria do capital humano. A partir dos anos 1980 o Banco Mundial e a Unesco começam a preparar uma agenda global para a educação: a aprovação do Proyecto Principal de Educación para América Latina y Caribe - PPE (1981), sob a defesa da universalização da educação básica, da superação do analfabetismo e da melhoria da qualidade da educação, impulsionou a formação do programa de Educação para Todos, que acabou por se constituir em um programa de educação seletiva para as massas (MELO, 2003).

A implantação do programa de Educação para Todos se consolidou nos anos 1990, sendo a Conferência de Jomtien o grande marco de uma "nova agenda para a educação básica", capaz de influenciar as ações para toda a década (MELO, 2003).

Segundo Leher (1999), analisando a mudança de correlação de forças entre Unesco e Banco Mundial, o protagonismo do Banco Mundial é verificado a partir de sua atuação direta nas funções da Unesco, sendo capaz de deslocar a ideologia do desenvolvimento, com a promessa de superação da pobreza, para a ideologia da globalização, que promete o aliviamento da pobreza. Esse processo de subordinação da Unesco se efetiva com a saída, em 1984, de EUA, Cingapura e Inglaterra, sendo suas prerrogativas assumidas pelo Banco Mundial (LEHER, 1999), o que custou sua autonomia financeira (MELO, 2003).

Tendo em vista as reformas educacionais dos países latino-americanos entre as décadas de 1980 e 1990, Leher (1999) verifica que as determinações do Banco Mundial e a ideologia da globalização consolidaram a mundialização da educação através de um processo de uniformização dos sistemas educacionais. Nesse movimento, destaca-se a tendência do sistema mundial de criar uma polarização entre os países centrais e os periféricos promovendo um verdadeiro

TrabalhoNecessário - www.uff.br/trabalhonecessario; Ano 11, № 17/2013. 


\section{Trabalhonecessário}

Issn: 1808 - 799X

ano 11, no $17-2013$

apartheid educacional planetário, haja vista o processo que "reduz a educação, de um direito social republicano e laico, a um 'serviço' distribuído 'a cada um, de acordo com seus recursos'" (LEHER, 1999, p.1).

A teoria do capital humano também é retomada com o intuito de legitimar a hegemonia neoliberal, justificando uma ação restrita do Estado ao ensino fundamental: "o alto retorno econômico do ensino fundamental é ressaltado e sua difusão é tida como o principal passaporte para uma melhor inserção do país na chamada globalização" (LEHER, 1999, p.2).

Segundo Hernandes (2007), o direcionamento dos organismos internacionais para a "paz mundial" e a reestruturação política, econômica e social dos países emerge enquanto uma preocupação do pós-guerra. É nessa perspectiva que, além de atentar para a segurança internacional, a ONU (Organização das Nações Unidas) também se voltou para os problemas econômicos, sociais, culturais e humanitários. Esses foram os antecedentes do surgimento da Organização para Cooperação Econômica Européia em 1948, que através do Plano Marshall encaminhava recursos dos Estados Unidos e Canadá para a reconstrução da Europa (HERNANDES, 2007, p.53).

Em 1961, a Organização para Cooperação Econômica Européia é substituída pela Organização para Cooperação e o Desenvolvimento Econômico (OCDE), que assume a função de "analisar políticas econômicas, financeiras, ambientais, industriais, trabalhistas e comerciais na esfera dos países membros e de outros com interesses pela organização", delineando, após os anos 1970, um perfil econômico responsável por reafirmar diretrizes de suporte aos países do capitalismo dependente (HERNANDES, 2007, p.54).

Tendo em vista o novo lugar ocupado pelo Brasil na divisão internacional do trabalho a partir da segunda metade dos anos 2000, diante da posição estratégica que o país passa a ocupar enquanto pólo aglutinador da expansão 


\section{Trabalhonecessário}

Issn: 1808 - 799X

ano $11, \mathrm{n}=17-2013$

capitalista na América do Sul e na África Ocidental, a OCDE ${ }^{11}$ torna-se um dos orientadores das mudanças de ênfase da política educacional brasileira nas décadas iniciais do século XXI.

A crise econômica iniciada em 2008 que atingiu os seus países membros repercutiu no posicionamento do organismo em relação a outros países. $O$ Conselho de Ministros da OCDE passou a estimular o engajamento ampliado do Brasil, China, Índia, África do Sul e Indonésia como países membros visando uma futura integração econômica para expansão de mercados dos países centrais ${ }^{12}$.

Para ser um membro permanente, a OCDE exige como requisito de ingresso à obtenção de certo Índice de Desenvolvimento Humano (IDH) e observância às metas de qualidade de ensino estabelecidas pelo seu Programa de Avaliação Internacional de Estudantes (PISA).

Em 2007, ano em que o Brasil foi convidado a aumentar seu engajamento com a OCDE, o goveno Lula da Silva implementou o Índice de Desenvolvimento da Educação Básica (IDEB) ${ }^{13}$, com alguns traços semelhantes ao PISA, para avaliar a natureza e o alcance da qualidade de ensino das escolas e das redes escolares brasileiras. Acreditamos que se trata de uma resposta objetiva que

\footnotetext{
${ }^{11}$ A OCDE é um órgão internacional e intergovernamental que reune atualmente 34 países capitalistas mais industrializados do mundo, tendo relações oficiais com outras organizações e organismos internacionais como OIT (Organização Internacional do Trabalho), FMI e muitos órgãos da ONU. Disponível em http://www.fazenda.gov.br/sain/pcn/PCN/ocde.asp, acesso em 18 de dezembro de 2012.

${ }^{12}$ Segundo informações divulgadas no portal do Ministério da Fazenda, "O relacionamento entre a OCDE e o Brasil aprofundou-se a partir de 1999, quando o Conselho da OCDE decidiu criar um programa direcionado ao Brasil. Uma maior aproximação entre o Brasil e a instituição ocorreu em 2000, quando o governo brasileiro assinou a 'Convenção de Combate à Corrupção de Autoridades Estrangeiras'.

Em maio de 2007, o Conselho Ministerial da OCDE decidiu 'fortalecer a cooperação da OCDE com o Brasil, China, Índia, Indonésia e África do Sul' por meio de programas de enhanced engagement (engajamento ampliado) com vistas a uma possível adesão à OCDE.", disponível em http://www.fazenda.gov.br/sain/pcn/PCN/ocde.asp, acesso em 18 de dezembro de 2012.

${ }^{13}$ Segundo o Instituto Nacional de Estudos e Pesquisas Educacionais Anísio Teixeira (INEP), o objetivo do IDEB se constitui em estabelecer metas para que o Brasil alcance o padrão de educação dos países da OCDE. Disponível em http://portalideb.inep.gov.br/index.php?option=com content\&view=article\&id=40\&ltemid=58, acesso em 18 de dezembro de 2012.
} 


\section{Trabalhonecessário}

Issn: 1808 - 799X

ano 11, no $17-2013$

credencia nosso país a se juntar à elite internacional organizada no interior da OCDE.

Para aprofundar a contextualização da América Latina, cabe ainda destacar a criação, em 1995, do Programa de Promoção da Reforma Educativa na América Latina (PREAL). Recuperando as bases do surgimento desse organismo, que nasceu de uma mobilização entre intelectuais orgânicos da classe burguesa, organismos empresariais e instâncias da aparelhagem estatal, Evangelista e Shiroma (2008) traçam os antecedentes do movimento Todos pela Educação. A "Conferência Ações de Responsabilidade Social em Educação: melhores práticas na América Latina" (2006), fruto da articulação entre Fundação Lemann, Jacobs e Grupo Gerdau - com a participação de membros do GT Profissionalização Docente (GTD) do PREAL, representante do PREAL e do Inter-American Dialogue $(I A D)$-, se constituiu na experiência da qual emergiu o documento conhecido por Compromisso Todos pela Educação.

O organismo Todos pela Educação (TPE) está contextualizado na iniciativa, em 2005, de um grupo de líderes empresariais, que através da noção de "incapacidade técnica e política dos governos na realização de políticas educacionais" impulsionou e influenciou a formulação do Decreto № 6.094 , em 2007 (MARTINS, 2009b). Nesse sentido, segundo Martins (2009b), esse movimento empresarial que deu origem ao TPE revela que

\footnotetext{
Sua penetração nas instâncias do Executivo e do Legislativo, e a transformação de sua proposição em lei, embora definida sob o argumento da "parceria", é, de fato, uma tática empregada nas relações de hegemonia. O que significa dizer que empresários organizados no TPE demonstram compreender que a configuração da sociedade brasileira na atualidade exige ações mais articuladas e requintadas, quando comparadas com as ações do passado.

[...] as estratégias e táticas empregadas impedem que amplas parcelas da população compreendam que os interesses defendidos em nome do "todos pela educação" não se refletem num projeto de educação única para todos. (MARTINS, 2009b, p.26-27)
}

Enfim, as iniciativas da ONU/Unesco, da OCDE, do Banco Mundial e do PREAL no movimento histórico revelam que os organismos internacionais atuam 
Issn: 1808 - 799X

ano $11, \mathrm{n}=17-2013$

de maneira decisiva na influência de políticas públicas e legitimam o projeto societário e educacional da hegemonia burguesa mundial, o que na atualidade se constitui na difusão dos princípios do neoliberalismo da Terceira Via. Cabe, agora, evidenciar as estratégias educacionais desenvolvidas pela classe dominante através da atuação dos organismos internacionais com base na ideologia da responsabilidade social.

\section{PROPOSTAS DOS ORGANISMOS INTERNACIONAIS E RESPONSABILIDADE SOCIAL NA EDUCAÇÃO}

Como ponto de partida para elucidar a assimilação/difusão dos princípios da responsabilidade social pelos organismos internacionais apresenta-se as formulações das Diretrizes da OCDE para Empresas Multinacionais (EMNs).

O documento "Responsabilidade social de empresas multinacionais: Diretrizes da OCDE" (TORRES, BEZERRA e HERNANDES, 2004) se constitui na primeira versão em português da publicação "Orientações para as Empresas multinacionais" da OCDE, divulgada em 2000.

Nas Diretrizes a OCDE demonstra superar a noção de filantropia de maneira a assimilar a ideologia da responsabilidade social, pois considera que as práticas das empresas socialmente responsáveis extrapolam as iniciativas voluntárias e a caridade, elencando a transparência e o acesso à informação enquanto princípios norteadores da responsabilidade social empresarial (TORRES, BEZERRA e HERNANDES, 2004, p.14).

O documento também evidencia o interesse em legitimar as Diretrizes na aparelhagem estatal, sugerindo que apesar delas não exigirem um cumprimento obrigatório, constituem uma norma amplamente reconhecida e promovida pelos Estados-membros da $\mathrm{OCDE}^{14}$, tendo o objetivo de criar uma relação de confiança

\footnotetext{
${ }^{14}$ Segundo o documento: "Os trinta membros da OCDE apoiaram as Diretrizes, e o número de TrabalhoNecessário - www.uff.br/trabalhonecessario; Ano 11, № 17/2013.
} 


\section{Trabalhonecessário}

Issn: 1808 - 799X

ano $11, \mathrm{n}=17-2013$

mútua entre as empresas e as autoridades governamentais (TORRES, BEZERRA e HERNANDES, 2004, p.17).

Além das Diretrizes da OCDE serem respaldadas através de referências a alguns documentos internacionais (Declaração Universal dos Direitos Humanos; Declaração da Organização Internacional do Trabalho; Declaração do Rio sobre Meio Ambiente e Desenvolvimento; e Declaração de Copenhague), Hernandes (2007) evidencia a legitimação desse código de conduta internacional ao estabelecer uma postura de obrigatoriedade em relação ao envolvimento do aparelho de Estado no cumprimento de normas internacionais, ainda que sejam voluntárias:

As Diretrizes da OCDE para EMNs tornaram-se um referencial para a responsabilidade social das empresas por reunir em um código de conduta internacional os principais temas em torno dos quais transitam as discussões sobre esse assunto e por envolver os governos nacionais em sua promoção.

Esse código de conduta, de caráter voluntário mas moralmente obrigatório, é um compilado de outros documentos fundamentais que, apesar de voluntário para as empresas é obrigatório aos Estados signatários da OCDE, na medida em que estão responsáveis por sua promoção e aplicação. (HERNANDES, 2007, p.103)

Esse discurso do "caráter voluntário mas moralmente obrigatório" das Diretrizes dá visibilidade ao papel estratégico da OCDE na correlação de forças, capaz de reafirmar um novo padrão de sociabilidade baseado na ideologia da responsabilidade social e contribuir na consolidação da hegemonia burguesa mundial.

Outra publicação que contribui para a organicidade do movimento da responsabilidade social é o "Livro Verde: Promover um quadro europeu para a responsabilidade social das empresas" (COMISSÃO DAS COMUNIDADES EUROPÉIAS, 2001). O documento também faz menção a variadas outras iniciativas para consolidar seu discurso. Através da referência ao Livro Branco,

países não-membros que as apóia está crescendo. Atualmente inclui Argentina, Brasil, Chile, Eslovênia, Estônia e Lituânia" (TORRES, BEZERRA e HERNANDES, 2004, p.16). 


\section{Trabalhonecessário}

Issn: 1808 - 799X

ano 11, no $17-2013$

reafirma-se o objetivo da Comissão Européia de criar a "Enterprise Europe" (uma Europa aberta, inovadora e empreendedora). A preocupação de articular o comportamento dos mercados com uma abordagem europeia da responsabilidade social está respaldada em iniciativas como o "Pacto Global" da ONU (2000), a "Declaração Tripartida sobre as Empresas Multinacionais e a Política Social" da OIT (1998) e as "Orientações para as Empresas Multinacionais" da OCDE (2000).

No Livro Verde difunde-se a formulação de que as estratégias de responsabilidade social se constituem em um investimento futuro para as empresas, promovendo uma verdadeira "concertação social" ao defender a mobilização de diversas partes "interessadas", como trabalhadores, acionistas, consumidores, poderes públicos e ONGs.

O documento destaca o Conselho Europeu de Lisboa, em 2000, enquanto um marco importante que associou o objetivo de desenvolvimento econômico ao movimento da responsabilidade social, voltado tanto para "uma economia dinâmica, competitiva, coesiva e baseada no conhecimento", quanto para práticas de "aprendizagem ao longo da vida, organização do trabalho, igualdade de oportunidades, inclusão social e desenvolvimento sustentável" (COMISSÃO DAS COMUNIDADES EUROPÉIAS, 2001, p.5).

Identifica-se que a Comissão realiza uma síntese entre desenvolvimento econômico e responsabilidade social, acompanhada pelas formulações de "economia do conhecimento" e "aprendizagem ao longo da vida", revelando a reafirmação da teoria do capital humano e a assimilação dos princípios da sociedade do conhecimento. A difusão da ideologia da sociedade do conhecimento e seu lema "aprender a aprender" (DUARTE, 2006) aparece articulada à teoria do capital humano, que através de uma leitura simplificadora do real opera uma inversão no qual o determinante vira determinado, o que significa considerar a educação como um instrumento de desenvolvimento econômico e mobilidade social (FRIGOTTO, 1993).

TrabalhoNecessário - www.uff.br/trabalhonecessario; Ano 11, № 17/2013. 
Issn: 1808 - 799X

ano 11, no $17-2013$

Para a Comissão, as práticas de responsabilidade social empresarial abrangem as dimensões interna e externa. A dimensão interna envolve "o investimento no capital humano, na saúde, na segurança e na gestão da mundança" (COMISSÃO DAS COMUNIDADES EUROPÉIAS, 2001, p.8). Em relação à gestão dos recursos humanos, destaca-se que a preocupação com a qualificação dos trabalhadores vem acompanhada por noções como "aprendizagem ao longo da vida", "responsabilização dos trabalhadores" e "empregabilidade" (COMISSÃO DAS COMUNIDADES EUROPÉIAS, 2001, p.8-9).

A dimensão externa das práticas de responsabilidade social se baseia, fundamentalmente, no desenvolvimento de capital social, considerando que a imagem da empresa no plano local também é um fator que influencia a competitividade. O compromisso das empresas em "causas locais" envolve:

oferta de espaços adicionais de formação, o apoio de acções de promoção ambiental, o recrutamento de pessoas vítimas de exclusão social, a disponibilização de estruturas de cuidados à infância para os filhos dos trabalhadores, parcerias com comunidades, o patrocínio de eventos culturais e desportivos a nível local ou donativos para acções de caridade. (COMISSÃO DAS COMUNIDADES EUROPÉIAS, 2001, p.13)

Enfim, o Livro Verde advoga pelo protagonismo europeu na organicidade da responsabilidade social, uma vez que a considera enquanto um meio eficaz e estratégico de incremento à produtividade e competitividade e de desenvolvimento de capital humano e capital social, contribuindo para a legitimação da hegemonia burguesa mundial.

Outro documento que reafirma o movimento da responsabilidade social é o Pacto Global da ONU. "O Pacto Global: Liderança das Empresas na Economia Mundial", lançado em 2000, tem por objetivo a adesão das empresas aos nove princípios universais em matéria de direitos humanos, de normas laborais e de ambiente:

\section{Direitos Humanos}

1. As empresas devem apoiar e respeitar a protecção dos direitos humanos proclamados

TrabalhoNecessário - www.uff.br/trabalhonecessario; Ano 11, № 17/2013. 


\section{Trabalhonecessário}

Issn: 1808 - 799X

ano $11, \mathrm{n}=17-2013$

internacionalmente; e

2. certificar-se de que não são cúmplices em violações dos direitos humanos.

\section{Normas Laborais}

3. As empresas devem apoiar a liberdade de associação e o reconhecimento do direito à negociação colectiva;

4. a eliminação de todas as formas de trabalho forçado e obrigatório;

5. a abolição efectiva do trabalho infantil; e

6. eliminar a discriminação no domínio do emprego e da actividade profissional.

\section{Ambiente}

7. As empresas devem apoiar uma abordagem cautelosa dos problemas ambientais;

8. levar a cabo iniciativas que visem promover uma mais responsabilidade ambiental;

9. incentivar o desenvolvimento e a difusão de tecnologias favoráveis ao ambiente.

(ORGANIZAÇÃO DAS NAÇÕES UNIDAS, 2001, p.2)

A ONU define o Pacto como "uma iniciativa voluntária que procura fornecer um quadro mundial para promover o crescimento sustentável e a boa cidadania, por meio da liderança empenhada e criativa das empresas" (ORGANIZAÇÃO DAS NAÇÕES UNIDAS, 2001, p.1). Também é evidenciado que "As empresas devem começar a agir de uma maneira diferente e produzir resultados tangíveis" (ORGANIZAÇÃO DAS NAÇÕES UNIDAS, 2001, p.3).

Nesse sentido, o Pacto Global reafirma o princípio da "sociedade civil ativa" do projeto neoliberal da Terceira Via de modo a conceber uma sociedade sem antagonismos na qual prevaleçam as noções de colaboracionismo, responsabilidade social e liberdade de escolhas individuais (MARTINS, 2009a), convocando a classe empresarial para liderar o processo de construção da nova sociabilidade.

Também é relevante destacar o documento "Parecer de Iniciativa sobre a Responsabilidade Social das Empresas" (PARECER, 2003), que traz constatações sobre o atraso de Portugal em relação aos demais países da União Europeia. O documento evidencia as "grandes desvantagens competitivas" do país e elege a RSE enquanto "um elemento-chave para o aumento da capacidade competitiva" (PARECER, 2003, p.22), demonstrando a preocupação de Portugal 


\section{Trabalhonecessário}

Issn: 1808 - 799X

ano 11, no $17-2013$

se engajar no movimento da responsabilidade social devido ao seu caráter orgânico e sua disseminação global.

Assim como o Livro Verde, o Parecer também sintetiza a ideologia da sociedade do conhecimento com a teoria do capital humano, uma vez que articula a ideia de "educação e formação contínua" com a noção de investimento em "recursos humanos":

A educação e a formação contínua é um dos temas mais frequentemente presentes, em resultado da própria necessidade das empresas que investem nos recursos humanos como uma peça básica da adaptação às dinâmicas da economia moderna. Tais práticas incluem programas de cooperação entre empresas, escolas, Universidades e centros de formação, a oferta de programas de estágios e outras acções destinadas a facilitar a transição dos jovens para a vida activa; a oferta de oportunidades de formação permanente a todos os trabalhadores; a cooperação em sistemas de certificação de competências adquiridas ao longo da vida de modo não formal e informal; e a criação de um ambiente organizacional propício à aprendizagem. (PARECER, 2003, p.6, grifos meus)

Verifica-se, portanto, um discurso que aposta nos retornos supostamente viabilizados pelo investimento em educação, agregando valor ao capital e incrementando a competitividade. "A educação, então, é o principal capital humano enquanto é concebida como produtora de capacidade de trabalho, potenciadora do fator trabalho. Nesse sentido é um investimento como qualquer outro" (FRIGOTTO, 1993, p.40).

Também é evidenciado o papel das empresas multinacionais e 0 compromisso tanto das "autoridades nacionais" quanto de "organismos como o Banco Mundial, o FMI, a OMC, a OIT e a OCDE" com o objetivo de desenvolver um "conjunto de normas mínimas internacionais, em especial no plano social" (PARECER, 2003, p.9), o que revela um movimento orgânico de construção da hegemonia burguesa mundial.

Vale ressaltar, ainda, a concepção do Parecer sobre o papel da aparelhagem estatal na educação:

O outro instrumento [dos poderes públicos] respeita ao sistema público de ensino e de

TrabalhoNecessário - www.uff.br/trabalhonecessario; Ano 11, № 17/2013. 


\title{
Trabalhonecessário
}

Issn: 1808 - 799X

ano $11, \mathrm{n}=17-2013$

\begin{abstract}
formação. Trata-se neste caso de introduzir nos currículos matérias relativas à responsabilidade social das empresas. Particularmente relevante será a contribuição das universidades que formam empresários, directores e quadros das empresas. A formação em direitos dos consumidores, de associações ambientalistas e de dirigentes e quadros dos parceiros sociais e civis, deveria igualmente ser melhor considerada. Por outro lado, numa óptica transversal, a preparação dos cidadãos para as implicações da responsabilidade social das empresas deveria ser considerada pelo sistema de ensino $\mathrm{e}$ de formação a todos os níveis. (PARECER, 2003, p.21, grifos meus)
\end{abstract}

A formulação do documento evidencia, portanto, a defesa da transferência direta de concepções empresariais para o universo escolar, o que se constitui na difusão dos modos de pensar, agir e sentir próprios do gerencialismo na educação.

As formulações presentes nas Diretrizes da OCDE, no Livro Verde, no Pacto Global e no Parecer convergem tanto no que se refere à adesão da responsabilidade social articulada aos princípios norteadores da Terceira Via, quanto em relação à centralidade da direção política dos organismos internacionais. As aproximações revelam que os organismos internacionais, enquanto aparelhos privados de hegemonia, disseminam um projeto educativo a serviço do mercado e voltado para a produtividade, competitividade e coesão social, elucidando a organicidade da ideologia da responsabilidade social e seu poder de legitimar um novo padrão de sociabilidade.

\section{BANCO MUNDIAL E UNESCO: FORMULAÇÕES SOBRE A EDUCAÇÃO NOS ANOS 2000}

Diante do panorama traçado sobre o movimento da responsabilidade social e sua articulação com o fenômeno da mundialização da educação, cabe esmiuçar os interesses dos organismos internacionais em influenciar projetos e políticas educacionais. Para tanto, buscou-se compreender as diretrizes educacionais disseminadas em dois documentos nos anos 2000: o documento "Melhorar o ensino e aprendizagem através de incentivos" ${ }^{\prime 15}$ de Vegas e Umansky com apoio

15 Documento escrito originalmente em espanhol, sendo todas as citações traduzidas em TrabalhoNecessário - www.uff.br/trabalhonecessario; Ano 11, № 17/2013. 


\section{Trabalhonecessário}

Issn: 1808 - 799X

ano 11, no $17-2013$

do Banco Mundial, de 2005; e o documento "Relatório de monitoramento de educação para todos" da Unesco, de 2008.

Sobre o discurso do Banco Mundial disseminado no estudo de Vegas e Umansky (2005), constata-se a concepção do organismo de que no mundo globalizado, que exige uma capacitação baseada em determinadas competências, os países latino-americanos apresentam uma educação básica de baixa qualidade. É nesse sentido que a educação é apontada como um meio eficaz para superar o subdesenvolvimento e a pobreza:

A América Latina é uma região que enfrenta enormes desafios, particularmente aqueles decorrentes do desenvolvimento, da pobreza e da desigualdade. [...] a educação em todos os níveis é reconhecida como um, se não o mais crítico, dos meios para enfrentar esses desafios. A democratização da educação, melhorando tanto a sua cobertura e qualidade, é fundamental para a superação da desigualdade social e econômica existente em toda a América Latina. Garantir que todas as crianças tenham a oportunidade de adquirir competências críticas em nível primário e secundário é fundamental para superar as barreiras que perpetuam 0 subdesenvolvimento e a pobreza (VEGAS e UMANSKY, 2005, p.2).

Verifica-se, portanto, a reafirmação da teoria do capital humano, uma vez que a educação, acompanhada pelo discurso das competências, é apontada como mola propulsora para atingir o desenvolvimento econômico e superar a desigualdade social, legitimando a inversão que transforma o determinante em determinado (FRIGOTTO, 1993).

Em síntese, o documento defende que alcançar a qualidade na educação básica significa empreender uma reforma da gestão, que deve passar a ser centrada na escola; realizar exames padronizados para promover incentivos baseados na avaliação dos professores e estabelecimentos diante do desempenho dos alunos; e valorizar os docentes (pelo mérito) através de esquemas de incentivo para premiá-los (VEGAS e UMANSKY, 2005).

A gestão escolar assume relevância com o objetivo de responsabilizar os professores pelos resultados e desempenho dos alunos, sendo que a

português de minha responsabilidade.

TrabalhoNecessário - www.uff.br/trabalhonecessario; Ano 11, № 17/2013. 
Issn: 1808 - 799X

ano 11, no $17-2013$

denominada "maior autoridade" das comunidades locais acaba por significar um verdadeiro mecanismo de controle sobre as instituições escolares e seus professores:

Em vários países da América Central, os governos têm instituído reformas de gestão escolar, que dão às comunidades locais maior autoridade sobre as escolas com a expectativa de aumentar a responsabilização do professor pelos resultados e, portanto, pelo desempenho acadêmico dos alunos. Estas reformas podem afetar os incentivos enfrentados pelos professores através do aumento de uma relação direta entre as escolas - os prestadores de serviços - e os pais, comunidades e estudantes - os clientes. (VEGAS e UMANSKY, 2005, p.20, grifos meus)

Apontando a avaliação enquanto outro indicador de qualidade, o documento considera os sistemas educacionais mexicano e chileno, baseados, respectivamente, nas premiações do professor e da escola, para destacar a importância de testes padronizados: "Ambos os mecanismos de incentivo tentam melhorar o ensino e a aprendizagem através da avaliação de professores e instituições educacionais a partir do desempenho dos alunos nor testes padronizados" (VEGAS e UMANSKY, 2005, p.42).

Em relação à valorização meritocrática dos docentes, o organismo internacional enfatiza a política de responsabilização dos professores como um instrumento eficaz para incentivar o alcance de bons resultados no processo de ensino e aprendizagem: "Em suma, para induzir os professores para um melhor desempenho e alcançar maiores níveis de aprendizagem dos alunos, os programas de incentivo do professor deveriam premiar professores que conseguem atender a esses" (VEGAS e UMANSKY, 2005, p.71).

Diante do discurso apresentado em Vegas e Umansky (2005), o Banco Mundial demonstra a concepção de que a qualidade da educação é afetada pela atuação do professor e sua formação profissional. Por mais que se constitua em uma delimitação de um problema real, não podemos ignorar o fato de o conteúdo ser indissociável da forma; ou seja, para além da crítica da secundarização do conhecimento sistematizado, é necessário analisarmos a essência das propostas para superar esta situação. A defesa da política de responsabilização 
Issn: 1808 - 799X

ano 11, no $17-2013$

(accountability) e dos modelos de gestão com seus mecanismos de pressão (expressos fundamentalmente nas avaliações) traz uma evidência concreta de que o Banco Mundial sustenta e aprova um sistema baseado em noções meritocráricas, o que reforça valores e comportamentos alinhados ao princípio do individualismo como valor moral radical.

Dessa forma, a defesa de uma reforma na gestão da escola está fundamentada em princípios meritocráticos e gerencialistas, o que também se articula com os denominados sete componentes de um sistema eficaz para atrair, reter e motivar os professores altamente qualificados, quais sejam, (1) infraestrutura e materiais de ensino adequados com recursos básicos; (2) clareza sobre o que se espera dos professores; (3) regras claras e transparentes para a seleção e alocação de professores; (4) monitoração e avaliação de ensino e aprendizagem; (5) liderança pedagógica e desenvolvimento profissional; (6) autonomia profissional e autoridade; (7) incentivos docentes eficazes (VEGAS e UMANSKY, 2005, p.18). Nesse sentido, constata-se uma relação direta com a chamada "eficácia escolar", na qual o foco no impacto das escolas sobre o ensino e a aprendizagem é justificado, tal como afirmam Brooke e Soares (2008), através do deslocamento das variáveis de "status" para as variáveis de "processo" Portanto, ambas as perspectivas, de Vegas e Umansky e de Brooke e Soares, elegem o gerencialismo na educação como suporte para sua fundamentação e expressam verdadeiras reafirmações da teoria do capital humano e do capital social.

16 O conteúdo das formulações sobre os sete componentes de um sistema eficaz de Vegas e Umansky (2005) converge com a formulação de Brooke e Soares (2008) sobre os onze fatores para escolas eficazes, quais sejam: (1) liderança profissional; (2) objetivos e visões compartilhados; (3) um ambiente de aprendizagem ordenado e um ambiente de trabalho atraente; (4) concentração no ensino e na aprendizagem com foco no desempenho; (5) ensino e objetivos claros com organização eficiente, clareza de propósitos, aulas bem estruturadas e ensino adaptável; (6) altas expectativas com fornecimento de desafios intelectuais; (7) incentivo positivo; (8) monitoramento do progresso com avaliação do desempenho do aluno e da escola; (9) direitos e responsabilidades do aluno; (10) parceria casa-escola; e (11) uma organização orientada à aprendizagem (BROOKE e SOARES, 2008, p.351). 


\section{Trabalhonecessário}

Issn: 1808 - $799 \mathrm{X}$

ano $11, \mathrm{n}=17-2013$

Em relação às formulações da Unesco (2008), verifica-se um movimento legitimador da mundialização da educação através da articulação entre a teoria do capital humano e a ideologia da sociedade do conhecimento: o organismo internacional enfatiza o reconhecimento do direito de todos à educação e à aprendizagem ao longo de toda a vida. Ressalta-se, também, que tal reconhecimento vem sendo divulgado desde 1990 com a Conferência Mundial de Educação para Todos, em Jomtien, e foi reafirmado em 2000 com a Conferência de Dacar, responsável por promover uma rede de atuação envolvendo 164 países comprometidos com os seis objetivos (a serem alcançados até 2015) do Marco de Ação de Educação para Todos (EPT):

1. Ampliar e aperfeiçoar os cuidados e a educação para a primeira infância, especialmente no caso das crianças mais vulneráveis e em situação de maior carência. 2. Assegurar que, até 2015 , todas as crianças, particularmente as meninas, vivendo em circunstâncias difíceis e as pertencentes a minorias étnicas, tenham acesso ao ensino primário gratuito, obrigatório e de boa qualidade.

3. Assegurar que sejam atendidas as necessidades de aprendizado de todos os jovens e adultos através de acesso eqüitativo a programas apropriados de aprendizagem e de treinamento para a vida.

4. Alcançar, até 2015, uma melhoria de 50\% nos níveis de alfabetização de adultos, especialmente no que se refere às mulheres, bem como acesso eqüitativo à educação básica e contínua para todos os adultos.

5. Eliminar, até 2005, as disparidades de gênero no ensino primário e secundário, alcançando, em 2015, igualdade de gêneros na educação, visando principalmente garantir que as meninas tenham acesso pleno e igualitário, bem como bom desempenho, no ensino primário de boa qualidade.

6. Melhorar todos os aspectos da qualidade da educação e assegurar a excelência de todos, de forma que resultados de aprendizagem reconhecidos e mensuráveis sejam alcançados por todos, especialmente em alfabetização lingüística e matemática e na capacitação essencial para a vida. (ORGANIZAÇÃO DAS NAÇÕES UNIDAS PARA A EDUCAÇÃO, A CIÊNCIA E A CULTURA, 2008, p.8)

Cabe destacar que a Unesco se coloca no papel de indutora de políticas públicas, atuando enquanto um verdadeiro aparelho privado de hegemonia, o que se constata em sua própria definição:

Neste contexto, a UNESCO vem exercendo suas funções colaborando com os países na formulação de suas políticas educacionais, desenvolvendo e difundindo meios inovadores e materiais sobre temas pertinentes à educação e intermediando parcerias entre financiadores, atores públicos, privados e não-governamentais para garantir melhor 


\section{Trabalhonecessário}

Issn: 1808 - 799X

ano 11, no $17-2013$

coordenação de esforços. (ORGANIZAÇÃO DAS NAÇÕES UNIDAS PARA A EDUCAÇẪO, A CIÊNCIA E A CULTURA, 2008, p.7)

Portanto, a indução de políticas públicas educacionais vem sendo motivada pela Unesco através das perspectivas de fragmentação e privatização sob a lógica da política de parcerias, coadunando forças para legitimar o movimento da responsabilidade social e reafirmar os princípios neoliberais da Terceira Via, notadamente o da sociedade civil ativa.

A Unesco também reafirma a perspectiva de um gerencialismo na educação, uma vez que revela a preocupação com uma qualidade da educação mensurada através de testes padronizados:

A qualidade da educação é um conceito sobre o qual há muito debate, especialmente sobre como quantificá-la. Os resultados de aprendizagem de alunos em testes padronizados têm sido usados em vários países, porém não estão disponíveis em bases comparáveis. Assim, a UNESCO utiliza como indicador da qualidade (meta 6) na composição do IDE a proporção de crianças que atingem a quinta série (ORGANIZAÇÃO DAS NAÇÕES UNIDAS PARA A EDUCAÇÃOO, A CIÊNCIA E A CULTURA, 2008, p.10) ${ }^{17}$.

Por fim, cabe ressaltar que o documento situa a atuação da Campanha Nacional pelo Direito à Educação (lançada em 1999 como um organismo vinculado à Unesco) na contexo das políticas públicas brasileiras de maneira a evidenciar o papel da sociedade civil na mobilização social, o que é reafirmado como um mecanismo para o desenvolvimento do EPT:

O alcance dos objetivos de EPT depende também da capacidade da sociedade civil de exercer a defesa da educação para todos, atuando principalmente no controle social das políticas governamentais e junto à comunidade internacional, como sugere o Relatório de Monitoramento Global de 2008. À UNESCO cabe o relevante papel de articular todas as forças na direção das metas firmadas em Dacar. (ORGANIZAÇÃO DAS NAÇÕES UNIDAS PARA A EDUCAÇÃO, A CIÊNCIA E A CULTURA, 2008, p.37)

A relevância dada à mobilização da sociedade civil para atingir os objetivos

\footnotetext{
17 O Índice de Desenvolvimento de Educação para Todos (IDE) é composto de indicadores quantitativos dos objetivos de "universalização da educação primária, alfabetização de adultos, paridade de gêneros e qualidade da educação" (ORGANIZAÇÂOO DAS NAÇÕES UNIDAS PARA A EDUCAÇÃO, A CIÊNCIA E A CULTURA, 2008, p.10).
}

TrabalhoNecessário - www.uff.br/trabalhonecessario; Ano 11, № 17/2013. 


\section{Trabalhonecessário}

Issn: 1808 - 799X

ano $11, \mathrm{n}^{\circ} 17-2013$

de EPT expressa uma adesão ao princípio da sociedade civil ativa, assim como revela um projeto educativo que fortalece o movimento da responsabilidade social e legitima a hegemonia do neoliberalismo da Terceira Via.

Enfim, cabe ressaltar que o lema "educação para todos" difundido pela Unesco vem acompanhado por uma operacionalização que não é para todos, uma vez que a defesa da qualidade na educação sob a lógica do gerencialismo se justifica pela necessidade de elevação dos patamares básicos de formação humana. Esse fenômeno, que se insere no movimento paradoxo em que a escola é hipertrofiada ao mesmo tempo em que é secundarizada, revela o interesse de elevação do patamar mínimo de racionalidade sendo coerente com um mínimo positivo para a ordem capitalista (SAVIANI, 1994).

\section{CONSIDERAÇÕES FINAIS}

As análises revelam que os organismos internacionais atuam enquanto verdadeiros aparelhos privados de hegemonia da burguesia mundial, uma vez que formulam e difundem experiências e práticas de uma formação técnica dos trabalhadores-colaboradores interessante para o mercado de trabalho e de uma conformação ético-política dos cidadãos de acordo com a sociabilidade burguesa, o que se constitui na indissociabilidade do trabalho/vida de maneira a consolidar uma (con)formação voltada para o capital que reafirma os princípios da responsabilidade social e legitima a mundialização da educação nos moldes de um capitalismo de face humanizada.

A agenda global para a educação assimilada/difundida pelos organismos internacionais está referenciada na nova pedagogia da hegemonia, que se manifesta na cultura escolar fundamentada nos valores e comportamentos do individualismo como valor moral radical, assim como nos planos, diretrizes e políticas educacionais baseadas nos princípios da privatização e fragmentação sob a lógica da política de parcerias. Enfim, os organismos internacionais

TrabalhoNecessário - www.uff.br/trabalhonecessario; Ano 11, № 17/2013. 
Issn: 1808 - 799X

ano 11, no $17-2013$

assumem direção na proposição de um gerencialismo na educação atravessado pela teoria do capital humano e pela ideologia da sociedade do conhecimento, elegendo o investimento em educação como suposto incremento para a competitividade global. 


\section{Trabalhonecessário}

Issn: 1808 - 799X

ano 11, no $17-2013$

\section{REFERENCIAS BIBLIOGRÁFICAS}

BROOKE, Nígel: SOARES, José Francisco. Pesquisa em eficácia escolar: origem e trajetórias. Belo Horizonte: Editora UFMG, 2008.

CHESNAIS, François. A mundialização do capital. Tradução Silvana Finzi Foá. - São Paulo: Xamã, 1996.

COMISSÃO DAS COMUNIDADES EUROPÉIAS. Livro Verde: Promover um quadro europeu para a responsabilidade social das empresas. Bruxelas, 2001.

DUARTE, Newton. Vigotski e o "aprender a aprender": crítica às apropriações neoliberais e pós-modernas da teoria vigotskiana. 4. ed. - Campinas, SP: Autores Associados, 2006.

EVANGELISTA, Olinda e SHIROMA, Eneida Oto. Redes para Reconversão Docente. In: Política, Educação e Cultura/ organização de Alexandre Felipe Fiuza, Gilmar Henrique da Conceição. - Cascavel: Edunioeste, 2008. (Coleção Sociedade, Estado e Educação; n. 1) p.33-53.

FONSECA, Marília. O Banco Mundial e a Gestão da Educação Brasileira. In: OLIVEIRA, Dalila de Andrade (org.) Gestão Democrática da Educação. Petrópolis, Vozes, 1997

FRIGOTTO, Gaudêncio. A produtividade da escola improdutiva. $4^{\mathrm{a}}$ ed. São Paulo: Cortez, 1993.

Novos fetiches mercantis da pseudoteoria do capital humano no contexto do capitalismo tardio. In: ANDRADE, Juarez de e PAIVA, Lauriana G. de (organizadores). As políticas públicas para a educação no Brasil contemporâneo: limites e contradições. Juiz de Fora: Ed. UFJF, 2011.

GRAMSCI, Antonio. Cadernos do cárcere. Vol. 3. Maquiavel. Notas sobre o Estado e a política. Tradução de Carlos Nelson Coutinho, Luiz Sérgio Henriques e Marco Aurélio Nogueira. Rio de Janeiro: Civilização Brasileira, 2000.

HERNANDES, Tânia dos Santos. Estudo sobre as Diretrizes da OCDE para Empresas Multinacionais e a responsabilidade social empresarial - $O$ papel do Estado e de organizações da sociedade civil na promoção de um comportamento socialmente responsável das empresas. Dissertação (Mestrado em Ciência Política). Niterói: Universidade Federal Fluminense, 2007. 


\section{Trabalhonecessário}

Issn: 1808 - 799X

ano $11, \mathrm{n}$ - $17-2013$

LEHER, Roberto. O BIRD e as reformas neoliberais na educação. Revista PUC Viva, № 5, Políticas de Educação para a América Latina, junho de 1999. Disponível em http://www.apropucsp.org.br/apropuc/index.php/revista-puc-viva/21edicao-5/1787-o-bird-e-as-reformas-neoliberais-na-educacao-, acesso em $11 / 2011$.

MARTINS, André Silva. A direita para o social: a educação para a sociabilidade no Brasil contemporâneo. Juiz de Fora: UFJF, 2009a.

A Educação Básica no Século XXI: o projeto do organismo “Todos pela Educação". Práxis Educativa, Ponta Grossa, v.4, n.1, p.21-28, jan.jun. 2009b.

MELO, Adriana Almeida Sales de. A mundialização da educação: o projeto neoliberal de sociedade e de educação no Brasil e na Venezuela. 2003. Tese (Doutorado em Educação) - Faculdade de Educação, Universidade Estadual de Campinas, Campinas, 2003.

NEVES, Lúcia Maria Wanderley (org.). A nova pedagogia da hegemonia. São Paulo: Xamã, 2005.

A direita para o social e a esquerda para o capital: intelectuais da nova pedagogia da hegemonia no Brasil. São Paulo: Xamã, 2010.

NEVES, Lúcia M.W; PRONKO, M. A. O mercado do conhecimento e o conhecimento para o mercado: da formação para o trabalho complexo no Brasil contemporâneo. Rio de Janeiro: EPSJV. 2008.

ORGANIZAÇÃO DAS NAÇÕES UNIDAS. O Pacto Global: Liderança das Empresas na Economia Mundial. Lisboa: Centro de Informações das Nações Unidas em Portugal, 2001. Disponível em www.onuportugal.pt, acesso em 04/2011.

ORGANIZAÇÃO DAS NAÇÕES UNIDAS PARA A EDUCAÇÃO, A CIÊNCIA E A CULTURA. Relatório de monitoramento de educação para todos Brasil 2008: educação para todos em 2015; alcançaremos a meta? - Brasília: UNESCO, 2008.

PARECER de Iniciativa sobre a Responsabilidade Social das Empresas. Aprovado no Plenário de 17 de janeiro de 2003. Lisboa, 2003.

PEREIRA, João Márcio Mendes. O Banco Mundial como ator político, 


\section{Trabalhonecessário}

Issn: 1808 - 799X

ano 11, no $17-2013$

intelectual e financeiro (1944-2008). 2009. Tese (Doutorado em História) Universidade Federal Fluminense, Niterói, 2009.

SAVIANI, Dermeval. O trabalho como princípio educativo frente às novas tecnologias. In: FERRETTI, C. J. et al. (Orgs.). Novas tecnologias, trabalho e educação: um debate multidisciplinar. Petrópolis: Vozes, 1994.

SOARES, Maria Clara Couto. Banco Mundial: políticas e reformas. In: TOMMASI, Livia De; WARDE, Miriam Jorge; HADDAD, Sérgio (organizadores). O Banco Mundial e as políticas educacionais. 2. ed. - São Paulo: Cortez, 1998.

SOUZA, Camila Azevedo. Organismos internacionais e responsabilidade social na educação: uma (con)formação voltada para o capital. Monografia (Bacharelado em Educação). Juiz de Fora: Universidade Federal de Juiz de Fora, 2013.

TORRES, Ciro, BEZERRA, Isaías e HERNANDES, Tânia (Orgs.). Responsabilidade social de empresas multinacionais: Diretrizes da OCDE. Rio de Janeiro: CERIS/IBASE, 2004.

VEGAS, Emiliana e UMANSKY, Ilana. Mejorar la enseñanza y el aprendizaje por medio de incentivos. ¿Qué lecciones nos entregan lãs reformas educativas de América Latina?. Washington, Banco Mundial, 2005.

VIEIRA, Sofia Lerche. Políticas Internacionais e Educação - Cooperação ou Intervenção? In: DOURADO, Luis Fernandes e PARO, Vitor. Políticas Públicas e Educação Básica. São Paulo. Xamã, 2001.

Data de recebimento: 02/04/2013

Data de aprovação: 23/10/2013 